
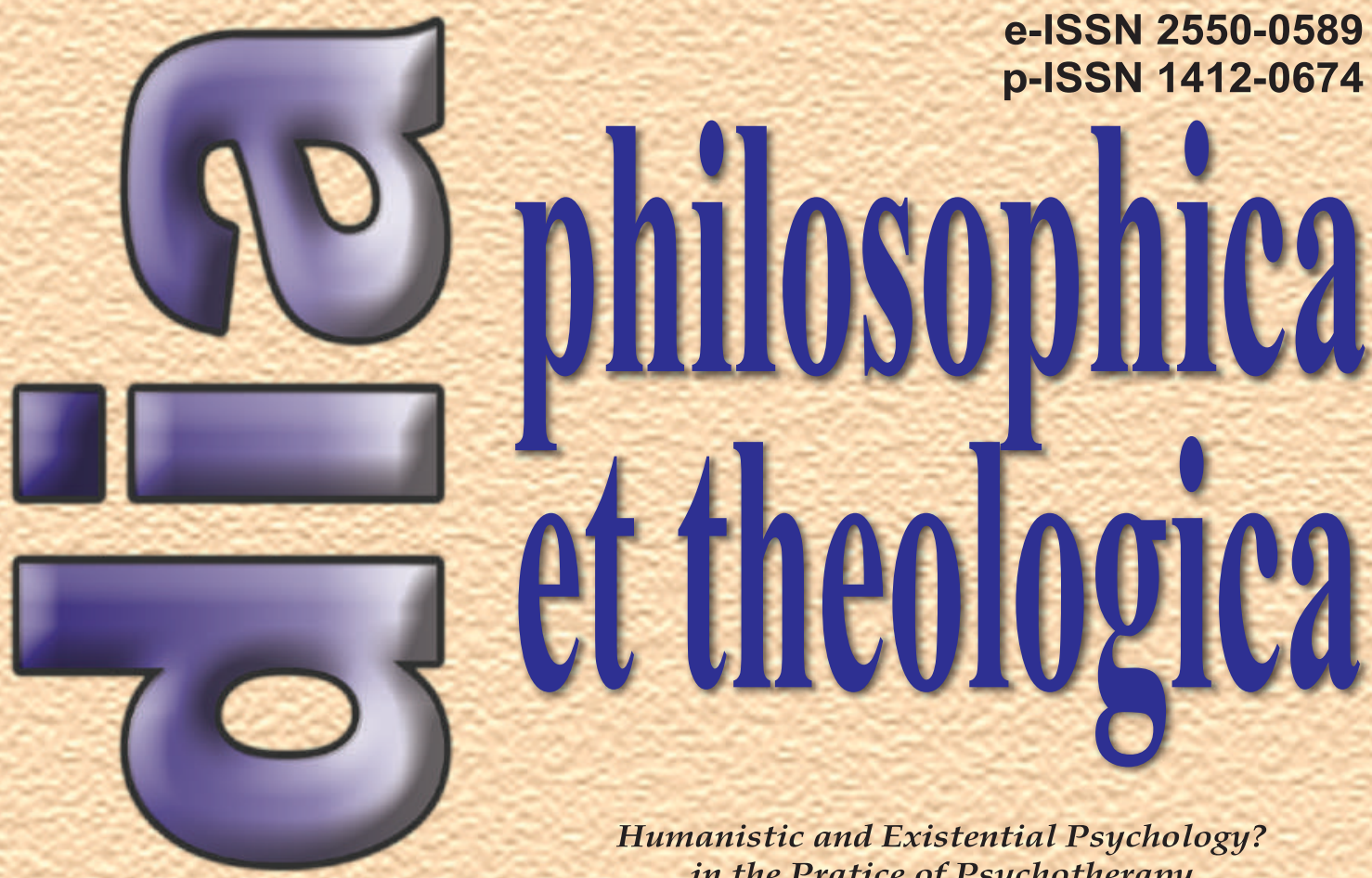

Humanistic and Existential Psychology? in the Pratice of Psychotherapy Aureliano Pacciolla

Visi Eskatologi - Kreatif da Eksemplaris - Terbuka Christanto Sema Raffan Paledung

Tentang Harmoni Antara Tuhan, Manusia dan Alam Dalam Tradisi Beduruk Di Dusun Medang Fransiskus Gregorius Nyaming
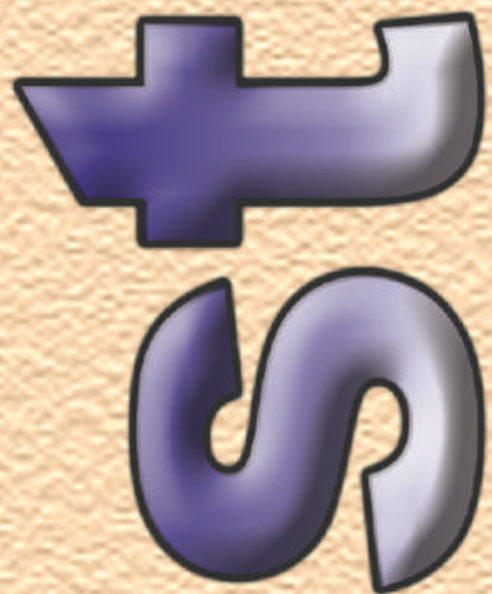

Tergeraklah Hatinya oleh Belas Kasihan Belajar dari Perumpamaan Orang Samaria yang Murah Hati (Luk. 10:25-37) Benny Phang

Hutan Dibabat, Masyarakat Melarat, Masa Depan Gelap I Ketut Gegel

Awal Moral Kristiani Edison R.L. Tinambunan $* * * * *$

TELAAH BUKU

Sekolah Tinggi Filsafat Teologi

Vol. 19 No. 1 April 2019 Widya Sasana, Malang 


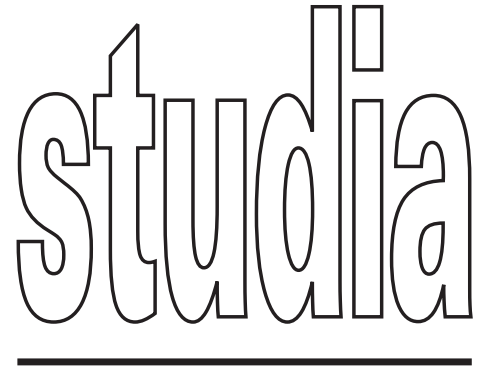

STUDIA PHILOSOPHICA ET THEOLOGICA (ISSN Print 1412-0674 and ISSN Online 2550-0589) is a bilingual (Indonesian and English language) and peer reviewed journal published by Center of Research of Widya Sasana School of Philosophy Theology, Malang. STUDIA specializes in researched papers related to contextualization and inculturation of theology and philosophy from inter-disciplinary-methodological point of view. Journal has 2 issues per year (April and October).

STUDIA welcomes philosophical and theological contributions from scholars with various background of disciplines. This journal uses English and Indonesian Language. STUDIA is an open access journal whose papers published is freely downloaded.

\section{FOCUS AND SCOPE:}

STUDIA focuses on philosophical and theological studies based on both literary and field researches. The emphasis of study is on systematic attempt of exploring seeds of Indonesian philosophy as well as contextualization and inculturationof theology in socio-political-historical atmosphere of Indonesia.

Scope of STUDIA covers various perspectives of philosophical and theological studies from interdisciplinary methodology and cultural-religious point of view of traditions.

\section{PUBLISHER :}

P3M Sekolah Tinggi Filsafat Teologi

Widya Sasana Malang

Jl. Terusan Rajabasa 2,

Malang 65146 Indonesia

Telp. $0341-552120$

Fax. $0341-566676$

Email : stftws@gmail.com

Website : ejournal.stftws.ac.id
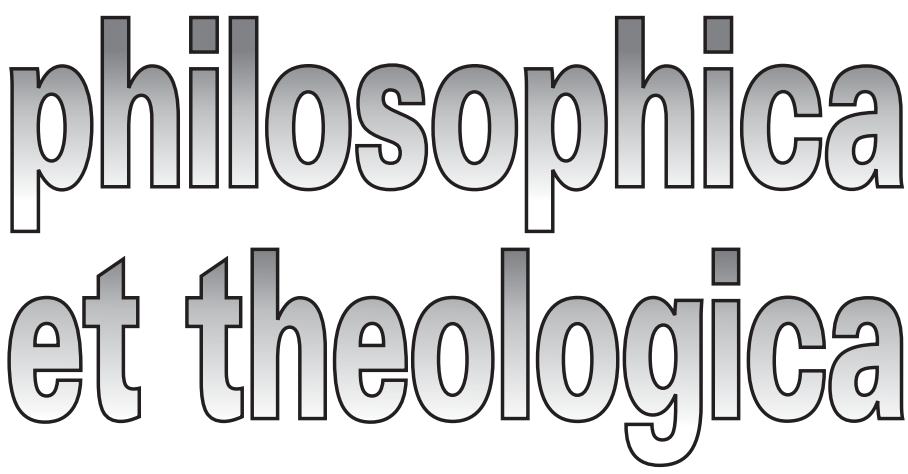

e-ISSN 2550-0589
p-ISSN 1412-0674

Editor

Edison RL. Tinambunan (Google Scholar; h-index: 1); Widya

Sasana College of Philosophy Theology, Malang. (Editor-in-Chief)

\section{Editorial Board}

FX. Eko Armada Riyanto (Google Scholar; h-index: 5); Widya Sasana College of Philosophy Theology, Malang.

Kurniawan Dwi Madyo Utomo (Google Scholar); Widya Sasana College of Philosophy Theology, Malang.

Pius Pandor (Google Scholar; h-index: 2); Widya Sasana College of Philosophy Theology, Malang.

Valentinus Saeng (Google Scholar; h-index: 2); Widya Sasana College of Philosophy Theology, Malang.

Yohanes I Wayan Marianta (Google Scholar); Widya Sasana College of Philosophy Theology, Malang.

Raymundus Made Sudhiarsa (Google Scholar; h-index: 2); Widya Sasana College of Philosophy Theology, Malang.

Alphonsus Catur Raharso (Google Scholar; h-index: 2); Widya Sasana College of Philosophy Theology, Malang.

Petrus Maria Handoko (Google Scholar; h-index: 2); Widya Sasana College of Philosophy Theology, Malang.

Antonius Denny Firmanto (Google Scholar; h-index: 2); Widya Sasana College of Philosophy Theology, Malang.

Carl Sterkens (Scopus ID: ... ; Google Scholar; h-index: 7); Katholic Radboud University, Nijmegen, Niederlands.

Daniel Franklin Pilario(Google Scholar; h-index: 4); Adamson University, Manila, Philippines.

Roland Tuazon (Google Scholar; h-index: 2); Adamson University, Manila, Philippines.

Emanuel P.D. Martasudjita (Scopus ID: 6026801; Google Scholar; h-index: 4); Sanata Dharma University, Yogyakarta.

Johanis Ohoitimur (Google Scholar; h-index: 3); Pineleng College, Manado.

Antonius Eddy Kristiyanto (Google Scholar; h-index: 5); Driyarkara College, Jakarta.

Mudjia Rahardja (Scopus ID: ... Google Scholar; h-index: 10); Maulana Malik Ibrahim Islamic State University, Malang.

Justinus Sudarminta (Google Scholar; h-index: 7); Driyarkara College, Jakarta.

\section{English Language Advisor}

Maria Lichmann (North Carolina)

Odilia Rahayu Widji Astuti

\section{Indonesian Language Advisor}

Didik Bagiyowinadi

\section{Information and Technology}

Imilda Retno Arum Sari

\section{Publication Frequency}

Studia Philosophicaet Theologica is published two times a year (April and October) 


\section{Author Guidelines}

1. Article must have150-word abstract in both English and Indonesian language and four or five keywords.

2. Article should be between 5000 and 8000 words, inclusive of references and footnotes.

3. Article must be a study based on either literary (text) or field research.

4. Article will be submitted in Word (single-spaced and 12-point font) for consideration by email attachment, beside online submission as required. Authors must log in before submit their article.

5. Headings:

- First-level headings (e.g. Introduction, Conclusion) should be in bold, with an initial capital letter for any proper nouns.

- Second-level headings should be in bold italics, with an initial capital letter for any proper nouns.

- Third-level headings should be in italics, with an initial capital letter for any proper nouns.

6. Notes and Bibliographies please click https://www.dropbox.com/s/y2nb9l3cvb9 fg47/Notes\%20and\%20Bibliography\%20Turabian\%20Style.pdf? $d l=0$.

7. Article submitted will be peer-reviewed by qualified academics; this process may take weeks or months. All submitted papers are subject to review of the editors, editorial board, and reviewers.

8. Author should be willing to respond to questions from readers of their articles; and in case there is correction, author must refine the article as soon as possible.

\section{Guidelines for Book Reviews}

1. Please include, at the beginning: Author, Title, Place, Publisher, Date, number of pages, ISBN of the book reviewed.

E.g., Taylor, Charles. A Secular Age. Cambridge: The Belknap Press of Harvard University Press, 2007. 874+x pp. ISBN-13: 978-0-674-02676-6.

2. The review begin with abstract, three or four keywords and continue with a brief overall description of the book.

3. The review may include:

- The content and its complexity of the book.

- Comments on the author's style and contribution of the book.

- Philosophical or theological methodology of presentation.

- Position of the philosophical or theological arguments in its field.

4. The preferred format for submissions is MS-Word.

5. Review should be about 1500 words long. The name, affiliation and email address of the reviewer should appear at the end of the review. 


\section{Studia Philosophica et Theologica E-ISSN 2550 - 0589 \\ ISSN 1412-0674 \\ Vol. 19 No. 1 April 2019 \\ Hal. 1 - 118}

\section{DAFTAR ISI}

\section{ARTIKEL}

Humanistic and Existential Psychology

in the Pratice of Psychotherapy

Aureliano Pacciolla

Visi Eskatologis - Kreatif dan Eksemplaris - Terbuka

Sebagai Model Kehadiran Kristen dalam Konteks Indonesia

Christanto Sema Raffan Paledung

Tentang Harmoni Antara Tuhan, Manusia dan Alam

Dalam Tradisi Beduruk Di Dusun Medang

Fransiskus Gregorius Nyaming

Tergeraklah Hatinya oleh Belas Kasihan: Belajar dari

Perumpamaan Orang Samaria yang Murah Hati (Luk. 10:25-37)

Dalam Mengasihi Embrio Manusia Sebagai Sesama

Benny Phang

$57-79$

Hutan Dibabat, Masyarakat Melarat, Masa Depan Gelap

Refleksi Teologis atas Keberpihakan Gereja Terhadap Masyarakat

Dalam Upaya Pelestarian Alam

I Ketut Gegel

Awal Moral Kristiani

Edison R.L. Tinambunan.

$98-114$ 


\section{TELAAH BUKU}

Relasionalitas Filsafat Fondasi Interpretasi:

Aku, Teks, Liyan, Fenomena

Donatus Sermada Kelen ........................................................ 115 - 118 


\section{Telaak Buku}

Judul Buku : Relasionalitas Filsafat Fondasi Interpretasi:

Aku, Teks, Liyan, Fenomena

Penulis : Armada Riyanto

Penerbit : PT Kanisius, 2018

Tebal : $\quad \mathbf{x i}+\mathbf{4 0 5}$

Manusia adalah makhluk yang "relasional". Karakter ini melekat secara alamiah dan hakiki dalam diri manusia sebagai subyek. Segala hal yang berhubungan dengan hidup dan kegiatan subyek untuk mewujudkan jati dirinya sebagai subyek yang relasional dipadatkan dalam kata kunci "relasionalitas" yang dibahasakan dalam istilah Indonesia "keterhubungan". Kekayaan makna yang termuat dalam kata kunci "relasionalitas" direfleksikan secara filsafiah oleh Armada Riyanto, CM, si penulis buku "Relasionalitas Filsafat Fondasi Interpretasi: Aku, Teks, Liyan, Fenomen". Penulisnya menyuguhkan kepada pembaca kegiatan berfilsafatnya yang sejalan dengan profesinya di bidang ilmu tersebut melalui karya tulisnya di bawah gagasan besar "Filsafat Relasionalitas".

Kekhasan dan keunggulan penulis, ketika berfilsafat tentang relasionalitas, terletak dalam skema dan metode berfilsafat. Sebagaimana para filsuf besar di Barat seperti Hegel, Immanuel Kant, Heidegger, dan lain-lain memperlihatkan metode dan skema berfilsafat yang menjadi milik khasnya saja, begitu pun penulis buku ini tidak kalah juga dengan para filsuf itu dalam soal skema dan metode berfilsafat. Penulis tidak menyusun karya ini menurut suatu skema dan metode tertentu yang sudah baku seperti bab demi bab dan sub bab demi sub bab, tetapi secara spontan dan intuitif mengekspresikan maknanya melalui penomoran seperti nomor satu hingga nomor sepuluh, dan dengan bebas dan lugas nomor demi nomor diberi judul bermakna yang keluar dari kedalaman hati sanubarinya untuk memudahkan penziarahan penafsiran. Judul yang bermakna tersebut berkisar pada soal "aku, teks, liyan, fenomen" yang dijadikan fondasi untuk proses penziarahan penafsiran terhadap relasionalitas.

Pembaca turut berziarah melalui nomor demi nomor yang tertera dalam buku ini. Pada bagian introduksi, penulis membiarkan pembaca belajar menjadi murid dari teks dalam penziarahan pencaharian makna. Dalam proses belajar tersebut, penulis menawarkan titik awal penziarahan dengan membuka dialog antara "Aku dan Teks" yang 
dituangkan dalam 31 poin. Dialog terjadi dalam konteks ruang dan waktu yang dimaknai sebagai pengalaman keseharian hidup di sini dan sekarang (hic et nunc). Hampir seluruh poin di dalam tuturan penulis berkisar antara pembaca dan teks yang keduanya berpijak pada makna. Pembaca berusaha mencapai makna kebenaran hidup yang sedang mengundang dan memanggil pembaca melalui teks. Dalam perjumpaan itu, pembaca tidak selamanya adalah subyek yang sealiran dan sekepercayaan dengan penulis teks, tetapi subyek sebagai "liyan". Karena itu, patutlah diakui bahwa betapa sulitnya menggapai makna asli dari teks yang sudah dieditkan itu. Pembaca perlu berimaginasi, membuat distansi terus menerus terhadap teks agar kebebasan pembaca tidak terkurung dan terbelenggu oleh teks yang mungkin tidak bersifat inklusif, membangun jembatan dialog, serta menjalankan pengujian (discernment)terhadap kebenaran hidup yang melekat pada pembaca dan pada teks. Penulis buku ini, Armada Riyanto, CM, masih lagi menggoreskan hal-hal yang termasuk dalam teks, seperti penulis teks, skema-skema arti dari teks, otoritas teks, layers teks (lapisan-lapisan teks yang mengacu pada dinamika pembaca), teks sebagai penafsiran pengarang terhadap realitas, teks yang inspiratif, teks api dan banyak hal lain lagi sehubungan dengan teks.

Ketika menggores tema "Aku dan Fenomen" serta "Filsafat Aku" pada nomor tiga dan empat, penulis memijakkan filsafatnya pada "fenomen dalam hadapannya dengan subyek aku sebagai keseluruhan manusia". Fenomen itu adalah realitas kehidupan yang terbentuk dari keterhubungan (relasionalitas) antara fenomen yang satu dengan fenomen yang lain. Karena itu, fenomen itu pada dasarnya bersifat naratif, dan narasi itu ditunjuk penulis melalui pencermatan sekilas terhadap sejarah filsafat tentang relasi aku dan fenomen. Filsafat "Aku" tidak akan terwujud tanpa fenomen. Maksudnya, kesadaran akulah yang dari hakekatnya adalah relasionalitas yang membiarkan fenomen menyerap ke dalam aku. Bahasa fenomenologi Husserl menyebutnya "kesadaran yang bersifat intensional". Dengan demikian, proses perwujudan relasionalitas berjalan bagai sebuah penziarahan hidup sehari-hari menuju kepenuhan hidup. Subyek aku dalam penziarahan ini belum penuh dan masih tetap berdialog.

Sesudah menulis tentang Filsafat $\mathrm{Aku}$, penulis secara spontan menuangkan gagasan tentang "Framework aku" (No.5). Framework aku adalah relasionalitas antara subyek dan subyek. Relasi yang demikian disebut intersubyektivitas. Relasi ini menampak dalam sosok "tubuh", subyek aku sebagai tubuh. Di dalam nomor ini rupanya tidak dibahasakan relasionalitas antara aku sebagai subyek dan liyan sebagai subyek, tetapi antara aku sebagai subyek dan aku sebagai subyek (subyek aku dan subyek $\mathrm{aku}$ ). Karena itu, penulis merasa perlu untuk menuangkan jati diri "liyan" pada nomor khusus (No.6). Di mana tempat "liyan"? Hal yang menarik 
dalam pemaparan tentang panorama konsep liyan dalam sejarah filsafat barat, penulis mencermati bahwa metafisika timur tidak memiliki konsep tentang liyan. Tidak ada sosok liyan dalam metafisika timur, karena hanya ada satu sosok sejati manusia, yaitu Self (Diri) yang identik dengan Brahman-Atman. Dalam konteks pemahaman modern, liyan dimaknai oleh penulis sebagai mereka yang terpinggirkan, mereka yang miskin dan tertindas, mereka yang lemah dan tak berdaya (powerless and voiceless).

Tema "Perempuan dan Liyan" dan "Liyan sebagai Orang Ketiga" digarap dalam Nomor 7 dan Nomor 8. Konteks masyarakat Indonesia terletak dalam kondisi yang "me-liyan-kan" perempuan. Artinya, perempuan adalah masyarakat Indonesia yang dikuasai oleh laki-laki secara kejam, bengis dan irasional. Kebudayaan maskulinlah yang menjiwai undang-undang pornografi dan pornoaksi. Pada hal, perempuan yang tercermin dalam tokoh-tokoh Bharatayuda seperti Sri Kandi, Kunti, Drupadi dan lain-lain justru membahasakan prinsip-prinsip etis-humanis, keutamaan dan cinta. Liyan sebagai orang ketiga dimaknai penulis dari sudut bahasa. Liyan adalah diri ketiga tunggal (dia) dan diri ketiga jamak (mereka). Makna linguistik ini menunjuk kepada kelompok manusia yang tidak termasuk dalam kata "kami, kita". Mereka adalah kelompok terpinggirkan, miskin, tertindas, lemah, tak berdaya dan tak bersuara ketika berhadapan dengan penguasa. Makna ini sudah diungkap pada tema tentang filsafat liyan, tapi di sini diulang dengan intensitas dan bahasa yang khas.

Dua nomor terakhir berbicara tentang Empati dalam Riset Fenomenologis (No.9) dan Cinta Relasional Aku dan Liyan (No.10). Penulis mengemukakan metode berfilsafatnya dalam menggarap relasionalitas. Riset fenomenologis bertujuan untuk mencari meaning atau makna pengalaman hidup manusia. Riset yang bersifat fenomenologis tentu mengisyaratkan bahwa haruslah ada relasi antara yang meneliti dan yang diteliti. Yang meneliti adalah peneliti dan yang diteliti adalah subyek yang diteliti (Subyek-Subyek). Untuk menggapai makna pengalaman manusia, baik peneliti maupun subyek yang diteliti saling merespons atas dasar sikap empati, yaitu kedalaman respons yang berasal dari kedua belah pihak. Dengan demikian, disposisi batin yang empatis ini dengan sendirinya bersifat relasional untuk membuahkan sebuah narasi dan bukan deskripsi, karena di dalam narasi, keaslian (genuinitas) relasi menampak. Pada nomor terakhir, si penulis yang dijiwai oleh spiriualitas kristiani menempatkan cinta ke dalam filsafat relasionalitas. Artinya, cinta adalah relasionalitas antara aku dan liyan, tapi liyan dalam kategori cinta adalah "Engkau" (Aku-Engkau) dan bukannya "dia atau mereka". Masyarakat adalah "kita" dalam cinta dan cinta dalam kita, dan itu sedang terwujud dalam ruang dan waktu perziarahan kita. 
Buku ini tentu merupakan sebuah buku filsafat yang penuh dengan wawasan-wawasan inspiratif. Horizon pembaca sungguh diperluas, dan khazanah gagasannya memperkaya hidup pembaca. Bahasanya lancar, mengalir dan mudah dipahami, meskipun dijejal dengan terminologi filsafiah. Bagi para akademisi, cendekiawan dan mahasiswa, buku ini layak dibaca. Masyarakat biasa bisa mencoba mendalaminya

Donatus Sermada Kelen 